\title{
Return Volatilities of U.S., U.K. and Australian Stock Markets on the Influence of Brazil Stock Markets
}

\author{
Yao-Cheng Tsai ${ }^{1}$, Wann-Jyi Horng ${ }^{2} \&$ Ming-Chi Huang ${ }^{3}$ \\ ${ }^{1}$ Department of Physical Education, Ling Tung University, Taichung, Taiwan \\ ${ }^{2}$ Department of Hospital and Health Care Administration, Chia Nan University of Pharmacy \& Science, Tainan, \\ Taiwan \\ ${ }^{3}$ General Education Center, Chia Nan University of Pharmacy \& Science, Tainan, Taiwan \\ Correspondence: Wann-Jyi Horng, Department of Hospital and Health Care Administration, Chia Nan University \\ of Pharmacy \& Science, No. 60, Erh-Jen Rd., Sec.1, Jen-Te, Tainan 71710, Taiwan. Tel: 886-6-266-4911 ext. \\ 5220 .
}

Received: October 6, 2016

Accepted: November 2, 2016

Online Published: November 18, 2016

doi:10.20849/abr.v1i2.84

URL: http://dx.doi.org/10.20849/abr.v1i2.84

\begin{abstract}
This paper proposes a three variable's double threshold-GRACH model, and uses this model to discuss U.S., U.K. and Australian stock return volatilities on the influence of the Brazil's stock market. The empirical result demonstrates that the three variable's double threshold-GARCH$(1,1)$ model is indeed appropriate, and also the response to the Brazil stock market has an asymmetrical effect. The empirical result also shows the different influence of the good news and the bad news on the eight kinds of the proposed model. Therefore, the information of U.S., U.K. and Australian stock return volatilities is able to affect the Brazil stock market returns' volatility.
\end{abstract}

Keywords: stock market, GARCH, asymmetrical effect, GJR-GARCH, double threshold-GARCH

\section{Introduction}

We know that the Brazil's measure of area is fifth in the World. The population of Brazil is also fifth in the World. Brazil is also one of BRICS, thus the global economical financial system also is the acting important status. Brazil has an important role to play in the global economical financial system. The GDP of Brazil is 8th in the global economical system (from The Economist, 2010-04). Brazil has a close relationship with the U.S., the U.K. and the Australian based on the trade and the circulation of capital, and the Australian, the U.S. and the U.K. are also powerful global economical nations. Therefore, how those three stock markets can impact Brazil's stock market is worth further discussion.

Among the financial time series non-linearity literature, Engle (1982) proposes the autoregressive conditionally heteroskedasticity (called ARCH) model and Bollerslev (1986) offers the generalization autoregressive conditionally heteroskedasticity (called GARCH) model. These kinds of models may catch the financial property that the variance is not a fixed characteristic. Nelson (1990) looks at stock price change research and discovers that they have both positive and negative relationships with future stock price volatility. The GARCH model supposes a settled time conditional variance for the preceding issue of conditional variance and an error term square function. Therefore, the error term's positive and negative values do not respond to its influence on the conditional variance equation. The conditional variance only changes along with the error term's value change, and cannot go along with the error term's positive and negative changes. To improve this flaw, Nelson (1991) presents an exponential GARCH model and Glosten, Jaganathan and Runkle (1993) give a GJR-GARCH model. These models are the so-called models of asymmetric GARCH. There are many research studies on the asymmetric problem, such as Horng and Lee (2008), Brooks (2001), Poon and Fung (2000) and Campell and Hentschel (1992).

This paper's main research goal is to discuss the influence of the U.S., the U.K. and the Australian stock return volatility on the Brazil's stock market, as well as the threshold stock price of return volatility rate's positive and negative values from those three markets. The paper constructs the three variable's double threshold-GARCH theoretical model and examines whether or not there is an asymmetrical influence between the markets. We 
understand there possibly creates an influence on the Brazil's stock market, by using the Student's t distribution of heavy tails for the stochastic error term. We also use the maximum likelihood algorithm method of BHHH (Berndt, et. al, 1974) to estimate the parameters of the proposed model. The software of EVIEWS and RATS are used in this paper. The organization of this paper is as follows. Section 2 states the data characteristics. Section 3 provides the proposed model and the empirical results, and the last section gives the conclusions.

\section{Data Characteristics}

\subsection{Data Sources}

In the sample selection, this research uses the Brazil Bovesp stock index, the Australian Sydney stock index, the S\&P500 index, and the FTSE 100 index as the sample. We select the sample period from January, 1998 to December, 2009 and use the stock indices for all the dates. The data originate from the Taiwan Economic Journal (TEJ), a large database in Taiwan.

\subsection{Return Rate Calculation and Basic Statistics}

To compute the stock return rates, in this paper, adopts the natural logarithm of the Brazil, the U.S., the U.K. and the Australian stock indices $\left(B R A_{t}, U S_{t}, U K_{t}, A U S_{t}\right)$ with one step difference and rides 100. From Table 1, the average return rate of the Brazil's stock index is 0.0710 , the average return rate of the U.S. stock index is 0.0054 , the average return rate of the U.K. stock index is 0.0010 , and the average return rate of the Australian stock index is 0.0230 . The risk of the Brazil's stock index return rate is 28.8325 , the risk of the U.S. stock index return rate is 10.2457 , the risk of the U.K. stock index return rate is 9.3843 , and the risk of the Australian stock index return rate is 5.4010, and therefore the risk of the Brazil stock price index return rate is the highest. From the Jarque-Bera statistics, under the null hypotheses of the normal distribution, we discover that the four stock return rates do not show a normal distribution. Moreover, the kurtosis is bigger than 3, and this result also demonstrates that the data have the phenomenon of a heavy tail distribution. From Table 2, the stock returns of the Brazil, U.S., U.K. and Australian shows a relationship.

Table 1. Basic statistics

\begin{tabular}{ccccc}
\hline Statistic & RBRA & RUS & RUK & RAUS \\
\hline Mean & 0.0710 & 0.0054 & 0.0010 & 0.0230 \\
S-D & 28.8325 & 10.2457 & 9.3843 & 5.4010 \\
Kurtosis & 14.5320 & 8.9320 & 7.3688 & 11.2021 \\
J-B & $14720^{* * *}$ & $3857^{* * *}$ & $2090^{* * *}$ & $7628^{* * *}$ \\
(p-value) & $(0.0000)$ & $(0.0000)$ & $(0.0000)$ & $(0.0000)$ \\
sample & 2629 & 2629 & 2629 & 2629 \\
\hline
\end{tabular}

Notes: (1) J-B N is the normal distribution test of Jarque-Bera.

(2) S-D is denoted the standard deviation.

(3) ${ }^{* * *}$ denotes significance at the level $1 \%$.

Table 2. The unconditional correlation values of the return rate for the four stock markets

\begin{tabular}{ccccc}
\hline Coefficient & RBRA & RUS & RUK & RAUS \\
RBRA & 1 & 0.5850 & 0.4241 & 0.1959 \\
\hline
\end{tabular}

This paper uses the unit root test of ADF (Dickey and Fuller, 1981) and KSS (Kapetanios, et. al, 2003). It shows that the stock sequences do not have the unit root, have stationary state sequences. Using Johansen's (1991) co-integration test, it shows that the Brazil stock market, the U.S. stock market, the U.K. stock market and the Australian stock market do not have a co-integration relation. Therefore, we are not need to consider the error correction model in this paper. We are used the methods of LM test (Engle, 1982), F test (Tsay, 2004) and L-B 
test (Ljung and box, 1978) to test the conditionally heteroskedasticity phenomenon. The empirical results of the ARCH effect test show that the Brazil's stock market exist the conditionally heteroskedasticity phenomenon. This result suggests that we can use the GARCH model to match and analyze it. Besides, the asymmetric test methods (Engle and Ng, 1993) are used as the following two methods: positive size bias test and joint test. By the positive size bias test and the joint test show that Brazil's stock market does have the asymmetrical effect, the details are omitted.

\section{Proposed Model and Empirical Results}

Based on the results of the asymmetry test as above, we can use the asymmetrically GARCH model to discuss the Brazil's stock return rate's volatility process., we follow the idea of self-exciting threshold autoregressive (SETAR) model (Tsay, 1989), and the ideas of the papers of Brooks (2001) and Tse and Tusi (2002), the idea of Liu, Zhao and Wang (2010), the idea of Horng and Lee (2008) and use the U.S., the U.K. and the Australian stock market returns' volatility as a threshold. After model process selection, in this paper, we may use the double threshold GARCH model to construct the Brazil's stock market return's volatility process, the double threshold GARCH(1, 1) model is illustrated as follows:

$$
\begin{aligned}
& R B R A_{t}=\left\{\begin{array}{l}
\phi_{10}+\phi_{11} R B R A_{t-1}+\phi_{12} R B R A_{t-2}+\phi_{13} R B R A_{t-3}+\phi_{14} R B R A_{t-4}+\phi_{15} R B R A_{t-5}+a_{t} \\
\phi_{20}+\phi_{21} R B R A_{t-1}+\phi_{22} R B R A_{t-2}+\phi_{23} R B R A_{t-3}+\phi_{24} R B R A_{t-4}+\phi_{25} R B R A_{t-5}+a_{t} \\
\phi_{30}+\phi_{31} R B R A_{t-1}+\phi_{32} R B R A_{t-2}+\phi_{33} R B R A_{t-3}+\phi_{34} R B R A_{t-4}+\phi_{35} R B R A_{t-5}+a_{t} \\
\phi_{40}+\phi_{41} R B R A_{t-1}+\phi_{42} R B R A_{t-2}+\phi_{43} R B R A_{t-3}+\phi_{44} R B R A_{t-4}+\phi_{45} R B R A_{t-5}+a_{t} \\
\phi_{50}+\phi_{51} R B R A_{t-1}+\phi_{52} R B R A_{t-2}+\phi_{53} R B R A_{t-3}+\phi_{54} R B R A_{t-4}+\phi_{55} R B R A_{t-5}+a_{t} \\
\phi_{60}+\phi_{61} R B R A_{t-1}+\phi_{62} R B R A_{t-2}+\phi_{63} R B R A_{t-3}+\phi_{64} R B R A_{t-4}+\phi_{65} R B R A_{t-5}+a_{t} \\
\phi_{70}+\phi_{71} R B R A_{t-1}+\phi_{72} R B R A_{t-2}+\phi_{73} R B R A_{t-3}+\phi_{74} R B R A_{t-4}+\phi_{75} R B R A_{t-5}+a_{t} \\
\phi_{80}+\phi_{81} R B R A_{t-1}+\phi_{82} R B R A_{t-2}+\phi_{83} R B R A_{t-3}+\phi_{84} R B R A_{t-4}+\phi_{85} R B R A_{t-5}+a_{t}
\end{array}\right. \\
& \begin{array}{l}
\text { if } R U S_{t-1} \leq 0, R U K_{t-1} \leq 0, R A U S_{t-1} \leq 0 \\
\text { if } R U S_{t-1} \leq 0, R U K_{t-1} \leq 0, R A U S_{t-1}>0 \\
\text { if } R U S_{t-1} \leq 0, R U K_{t-1}>0, R A U S_{t-1} \leq 0 \\
\text { if } R U S_{t-1}>0, R U K_{t-1} \leq 0, R A U S_{t-1} \leq 0 \\
\text { if } \\
\text { if } R U S_{t-1}>0, R U K_{t-1}>0, R A U S_{t-1} \leq 0 \\
\text { if } R U S_{t-1}>0, R U K_{t-1} \leq 0, R A U S_{t-1}>0 \\
\text { if } R U S_{t-1} \leq 0, R U K_{t-1}>0, R A U S_{t-1}>0 \\
\text { if } R U S_{t-1}>0, R U K_{t-1}>0, R A U S_{t-1}>0
\end{array} \\
& a_{t}=\sqrt{((v-2) / v) h_{t}} \varepsilon_{t}, \varepsilon_{t} \sim t_{v}(0,1),
\end{aligned}
$$

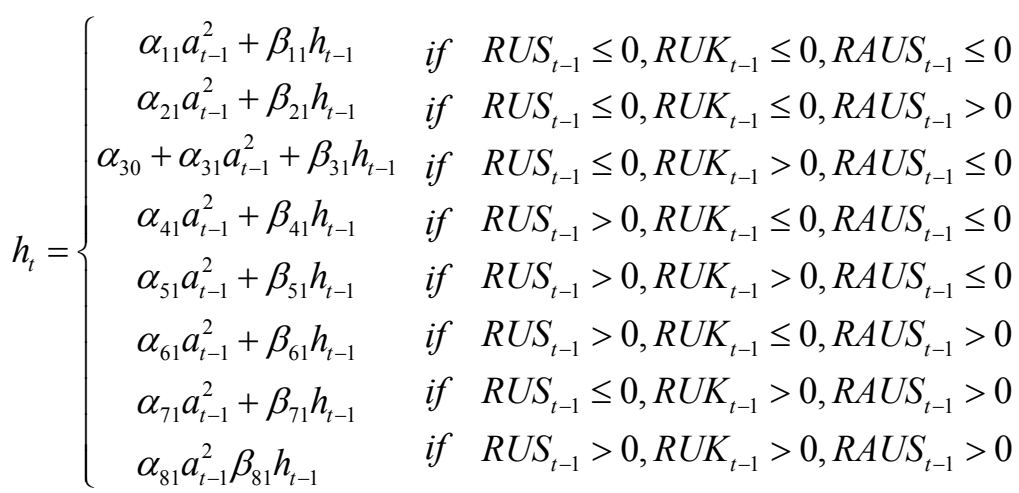

where $t_{v}(0,1)$ is defined as above, with $R U S_{\mathrm{t}}>0$ expresses the stock return rate of the U.S. for the positive value (good news) and $R U S_{\mathrm{t}} \leq 0$ expresses the stock return rate of the U.S. for the negative value (bad news); $R U K_{\mathrm{t}}>0$ 
expressing the stock return rate of the U.K. for the positive value (good news) and $R U K_{\mathrm{t}} \leq 0$ expressing the stock return rate of the U.K. for the negative value (bad news); $R A U S_{\mathrm{t}}>0$ expresses the stock return rate of the Australian for the positive value (good news) and $R A U S_{\mathrm{t}} \leq 0$ expresses the stock return rate of the Australian for the negative value (bad news).

By the estimated results of the three variable's double threshold-GARCH $(1,1)$ model in Table 3, we test the estimated value of the parameters' coefficients to be significant or not with a P-value. The empirical result shows that, for example, when the stock price return rate of the U.S., U.K. and Australian are all negative values, the Brazil's stock return rate receives the previous four day's return's influence of the Brazil's stock return rate ( $\left.\phi_{14}=-0.0837\right)$ - namely, it is significant under the $10 \%$ significance level. The Brazil's stock return rate does not receive the previous one to third day's influence of the Brazil's stock return rate at the $10 \%$ level of significance. The Brazil's stock return rate does not receive the previous fifth day's influence of the Brazil's stock return rate at the $10 \%$ level of significance. When the stock return rate of the U.S., U.K. and Australian are all positive values, the Brazil's stock return rate also receives the previous second day's return influence of the Brazil ( $\phi_{82}=-0.0888$ )- namely, it is significant at the $10 \%$ level of significance. The Brazil's stock return rate does not receive the previous one day's influence of the Brazil's stock return rate at the $10 \%$ level of significance- namely, it is not significant under the $10 \%$ significance level. The Brazil's stock return rate does not also receive the previous third to fifth day's return influence of the Brazil- namely, it is not significant under the $10 \%$ significance level.

In Table 3, for example, under the stock return rate of the U.S. and the U.K. are both negative and the stock

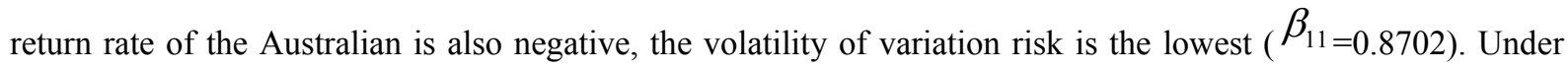
the stock return rate of the U.S. and Australian are both negative and the stock return rate of the U.K. is positive, the Brazil's stock return rate has also a fixed risk $\left(\alpha_{30}=1.9988\right)$. Under the stock return rate of the U.S. and the U.K. are both positive and the stock return rate of the Australian is negative, the volatility of variation risk is the highest $\left(\beta_{51}=0.9820\right)$. Moreover, $\alpha_{11}+\beta_{11}=1, \alpha_{21}+\beta_{21}=1, \alpha_{31}+\beta_{31}=1, \alpha_{41}+\beta_{41}=1$, $\alpha_{51}+\beta_{51}=1, \alpha_{61}+\beta_{61}=1, \alpha_{71}+\beta_{71}=1$, and $\alpha_{81}+\beta_{81}=1$ conforms to parameter of the IGARCH model's condition supposition. Besides, the test result of the likelihood ratio test is supported the three variable's double threshold-IGARCH $(1,1)$ model, which is significant under the $1 \%$ significance level, the detail is omitted. Therefore, the Brazil's stock return rate volatility has an asymmetrical effect. This will, however, have the different variation risks of the stock return rates in the U.S., the U.K. and the Australian where they have positive and negative values under eight kinds of situations. The traditional GARCH model is unable to respond to this information, but the three variable's double threshold-IGARCH$(1,1)$ model might truly catch the Brazil's stock return rate volatility process. Therefore, the explanation ability of the three variable's double threshold-IGARCH $(1,1)$ model is better than the traditional model of GARCH. 
Table 3. Parameter estimation of the proposed model

\begin{tabular}{|c|c|c|c|c|c|}
\hline Parameters & $\phi_{10}$ & $\phi_{20}$ & $\phi_{30}$ & $\phi_{40}$ & $\phi_{50}$ \\
\hline Coefficient & 0.1768 & 0.1842 & -0.1056 & 0.3680 & 0.1833 \\
\hline (p-value) & $(0.0655)$ & $(0.1123)$ & $(0.5045)$ & $(0.0011)$ & $(0.1210)$ \\
\hline Parameters & $\phi_{60}$ & $\phi_{70}$ & $\phi_{80}$ & $\phi_{11}$ & $\phi_{12}$ \\
\hline Coefficient & 0.3876 & 0.1584 & 0.1544 & 0.0420 & -0.0077 \\
\hline (p-value) & $(0.0072)$ & $(0.1700)$ & $(0.1351)$ & $(0.3865)$ & $(0.8649)$ \\
\hline Parameters & $\phi_{13}$ & $\phi_{14}$ & $\phi_{15}$ & $\phi_{21}$ & $\phi_{22}$ \\
\hline Coefficient & -0.0117 & -0.0837 & -0.0028 & 0.0479 & -0.0473 \\
\hline (p-value) & $(0.7849)$ & $(0.0504)$ & $(0.9456)$ & $(0.4506)$ & $(0.4204)$ \\
\hline Parameters & $\phi_{23}$ & $\phi_{24}$ & $\phi_{25}$ & $\phi_{31}$ & $\phi_{32}$ \\
\hline Coefficient & -0.0151 & -0.0290 & -0.0334 & -0.0446 & -0.0650 \\
\hline (p-value) & $(0.7783)$ & $(0.6212)$ & $(0.4727)$ & $(0.6282)$ & $(0.3583)$ \\
\hline Parameters & $\phi_{33}$ & $\phi_{34}$ & $\phi_{35}$ & $\phi_{41}$ & $\phi_{42}$ \\
\hline Coefficient & 0.0854 & 0.1379 & 0.0105 & 0.1145 & 0.0591 \\
\hline (p-value) & $(0.2851)$ & $(0.0625)$ & $(0.8881)$ & $(0.0873)$ & $(0.3338)$ \\
\hline Parameters & $\phi_{43}$ & $\phi_{44}$ & $\phi_{45}$ & $\phi_{51}$ & $\phi_{52}$ \\
\hline Coefficient & -0.0615 & -0.0095 & -0.1510 & -0.0607 & -0.0003 \\
\hline (p-value) & $(0.2224)$ & $(0.8752)$ & $(0.0121)$ & $(0.3619)$ & $(0.9956)$ \\
\hline Parameters & $\phi_{53}$ & $\phi_{54}$ & $\phi_{55}$ & $\phi_{61}$ & $\phi_{62}$ \\
\hline Coefficient & -0.0125 & -0.0024 & -0.0580 & -0.0281 & -0.1270 \\
\hline (p-value) & $(0.8256)$ & $(0.9636)$ & $(0.3592)$ & $(0.7643)$ & $(0.0856)$ \\
\hline Parameters & $\phi_{63}$ & $\phi_{64}$ & $\phi_{65}$ & $\phi_{71}$ & $\phi_{72}$ \\
\hline Coefficient & -0.0041 & -0.0387 & -0.0541 & -0.0054 & -0.0031 \\
\hline (p-value) & $(0.9491)$ & $(0.6302)$ & $(0.4435)$ & $(0.9459)$ & $(0.9614)$ \\
\hline Parameters & $\phi_{73}$ & $\phi_{74}$ & $\phi_{75}$ & $\phi_{81}$ & $\phi_{82}$ \\
\hline Coefficient & 0.0631 & -0.0651 & 0.0134 & 0.0046 & -0.0888 \\
\hline (p-value) & $(0.3139)$ & $(0.2381)$ & $(0.8253)$ & $(0.9290)$ & $(0.0623)$ \\
\hline Parameters & $\phi_{83}$ & $\phi_{84}$ & $\phi_{85}$ & & \\
\hline Coefficient & -0.0130 & 0.0191 & -0.0457 & & \\
\hline (p-value) & $(0.7675)$ & $(0.6753)$ & $(0.3225)$ & & \\
\hline Parameters & $\alpha_{11}$ & $\beta_{11}$ & $\alpha_{21}$ & $\beta_{21}$ & $\alpha_{30}$ \\
\hline Coefficient & 0.1298 & 0.8702 & 0.0862 & 0.9138 & 1.9988 \\
\hline (p-value) & $(0.0000)$ & $(0.0000)$ & $(0.0064)$ & $(0.0000)$ & $(0.0000)$ \\
\hline
\end{tabular}




\begin{tabular}{cccccc}
\hline Parameters & $\alpha_{31}$ & $\beta_{31}$ & $\alpha_{41}$ & $\beta_{41}$ & $\alpha_{51}$ \\
\hline Coefficient & 0.1155 & 0.8845 & 0.0242 & 0.9758 & 0.0180 \\
\hline (p-value) & $(0.0218)$ & $(0.0000)$ & $(0.0000)$ & $(0.0000)$ & $(0.0000)$ \\
\hline Parameters & $\beta_{51}$ & $\alpha_{61}$ & $\beta_{61}$ & $\alpha_{71}$ & $\beta_{71}$ \\
\hline Coefficient & 0.9820 & 0.0502 & 0.9498 & 0.0717 & 0.9283 \\
\hline (p-value) & $(0.0000)$ & $(0.0000)$ & $(0.0000)$ & $(0.0000)$ & $(0.0000)$ \\
\hline Parameters & $\alpha_{81}$ & $\beta_{81}$ & $v$ & & \\
\hline Coefficient & 0.0293 & 0.9707 & 8.4026 & & \\
\hline (p-value) & $(0.0555)$ & $(0.0000)$ & $(0.0000)$ & &
\end{tabular}

Notes: $p$-value $<\alpha$ denote significance $(\alpha=1 \%, \alpha=5 \%, \alpha=10 \%)$.

To test the inappropriateness of the double threshold $\operatorname{IGARCH}(1,1)$ model, the test method of Ljung and Box (1978) is used to examine autocorrelation of the standard residual error. This model does not show an autocorrelation of the standard residual error. Therefore, the three variable's double threshold $\operatorname{IGARCH}(1,1)$ model are more appropriate.

\section{Conclusions}

Empirical result demonstrates that the three variable's double threshold- $\operatorname{IGARCH}(1,1)$ model's fittings is appropriate when discussing the Brazil's stock market. The Brazil stock market has an asymmetrical effect. This can also respond to good news and bad news of the eight kinds of combinations, which allows it to have different variation risk. The empirical result also shows that the stock return volatilities of the U.S., the U.K. and the Australian truly have an influence on the Brazil's stock return volatility process.

\section{References}

Berndt, E.K., Hall, B.H., Hall, R.E., \& Hausman, J.A. (1974). Estimation and inference in nonlinear structural models. Annals of Economic and Social Measurement, 4, 653-665.

Bollerslev, T. (1986). Generalized autoregressive conditional heteroskedasticity. Journal of Econometrics, 31, 307-327. http://dx.doi.org/10.1016/0304-4076(86)90063-1

Brooks, C. (2001). A double-threshold GARCH model for the French Franc/Deutschmark exchange rate. Journal of Forecasting, 20, 135-143. http://dx.doi.org/10.1002/1099-131X(200103)20:2<135::AID-FOR780>3.0.CO;2-R

Campell, J.Y., \& Hentschel, L. (1992). No news is good news: an asymmetric model of changing volatility in stock returns. Journal of Financial Economics, 31, 281-318. http://dx.doi.org/10.1016/0304-405X(92)90037-X

Dickey, D.A., \& Fuller, W.A. (1981). Likelihood ratio statistics for autoregressive time series with a unit root. Econometrica, 49, 1057-1072. http://dx.doi.org/10.2307/1912517

Engle, R.F. (1982). Autoregressive conditional heteroskedasticity with estimates of the variance of United Kingdom Inflation. Econometrica, 50, 987-1007. http://dx.doi.org/10.2307/1912773

Engle, R.F., \& Ng, V.K. (1993). Measuring and testing the impact of news on volatility. Journal of Finance, 48(5), 1749-1777. http://dx.doi.org/10.1111/j.1540-6261.1993.tb05127.x

Glosten, L.R., Jagannathan, R., \& Runkle, D.E. (1993). On the relation between the expected value and the volatility on the nominal excess returns on stocks. Journal of Finance, 48, 1779-1801. http://dx.doi.org/10.1111/j.1540-6261.1993.tb05128.x

Horng, W.J., \& Lee, J.Y. (2008). An impact of the U.S. and the U.K. return rates' volatility on the stock market returns: an evidence study of Germany's stock market Returns. Proceedings IEEE Computer Society, 2, ICCIT2008, 1159-1163. 
Johansen, S. (1991). Estimation and hypothesis testing of cointegration vector in Gaussian vector autoregressive models. Econometrica, 52, 389-402. http://dx.doi.org/10.1016/0304-4076(92)90019-N

Kapetanios, G., Shin, Y., \& Snell, A. (2003). Testing for a unit root in the nonlinear STAR framework. Journal of Econometrics, 112(2), 359-379. http://dx.doi.org/10.1016/S0304-4076(02)00202-6

Liu, Y., Zhao, J., \& Wang, W. (2010). A time series based prediction method for a coke oven gas system in steel industry. ICICIC Express Letters, 4(4), 1373-1378.

Ljung, G.M., \& Box, G.E.P. (1978). On a measure of lack of fit in time series models. Biometrika, 5(2), 297-303. http://dx.doi.org/10.1093/biomet/65.2.297

Nelson, D.B. (1990). Stationarity and persistence in the GARCH(1,1) model. Econometric Theory, 6, 318-334. http://dx.doi.org/10.1017/S0266466600005296

Nelson, D.B. (1991). Conditional heteroscedasticity in asset returns: a new approach. Econometrica, 59, 347-370. http://dx.doi.org/10.2307/2938260

Poon, W.P.H., \& Fung, H.G. (2000). Redchips or H shares: which China-backed securities process information the fastest? Journal of Multinational Financial Management, 10, 315-343. http://dx.doi.org/10.1016/S1042-444X(00)00026-8

Tsay, R.S. (1989). Testing and modeling threshold autoregressive processes. Journal of the American Statistical Association, 84, 231-240. http://dx.doi.org/10.1080/01621459.1989.10478760

Tsay, R.S. (2004). Analysis of Financial Time Series. John Wiley \& Sons, New York.

Tse, Y.K., \& Tsui, Albert K.C. (2002). A multivariate GARCH model with time-varying correlations, Journal of Business \& Economic Statistics, 20, 351-362. http://dx.doi.org/10.1198/073500102288618496

\section{Copyrights}

Copyright for this article is retained by the author(s), with first publication rights granted to the journal.

This is an open-access article distributed under the terms and conditions of the Creative Commons Attribution license (http://creativecommons.org/licenses/by/4.0/). 